\title{
Sistem Kendali Mutu Beras Pada Kelompok Tani Berbasis Sistem Pendukung Keputusan
}

\author{
Khairul $^{1 *}$, Barany Fachri² \\ ${ }^{123}$ Prodi Sistem Komputer, Fakultas Sains dan Teknologi, Universitas Pembangunan Panca Budi \\ Medan \\ e-mail: 1khairul@dosen.pancabudi.ac.id, 2barany_fachri@dosen.pancabudi.ac.id,
}

\begin{abstract}
Food commodities are one of the important commodities in human life. The important role of food ingredients is the basis for the development of the business world related to food commodities and processed ingredients from every food ingredient that exists. One of the dominant food commodities in almost all Asian countries is rice, especially for countries in the Southeast Asia region. Rice is rice which has been removed by grinding and polishing using a peeler and huller and polisher. Rice is an important commodity because it is a staple food that must be fulfilled at any time. Decision support system (SPK), as a computer-based system that assists in the decision making process. SPK as an adaptive, interactive, flexible computer-based information system, specifically developed to support unstructured management solutions to improve the quality of decision making. In this study the design and making of a decision support system was carried out to determine the quality of android-based rice using the weighted product method, because it saw the number of different farmer groups and types of rice.
\end{abstract}

Keywords: Android, Rice, Decision Support System, Weighted Product

\begin{abstract}
Abstrak- Komoditas pangan merupakan salah satu komoditas penting dalam kehidupan manusia. Peranan penting bahan pangan tersebut menjadi dasar untuk perkembangan dunia usaha yang berkaitan dengan komoditas pangan dan bahan olahan dari setiap bahan pangan yang ada. Salah satu komoditas pangan yang menjadi bahan pangan dominan di hampir semua negara asia adalah beras, khususnya untuk negara-negara di kawasan Asia Tenggara. Beras adalah gabah yang bagian kulitnya sudah dibuang dengan cara digiling dan disosoh menggunakan alat pengupas dan penggiling (huller) serta penyosoh (polisher). Beras merupakan komoditas yang penting karena merupakan kebutuhan pangan pokok yang setiap saat harus dapat dipenuhi. Sistem pendukung keputusan (SPK), sebagai sebuah sistem berbasis komputer yang membantu dalam proses pengambilan keputusan. SPK sebagai sistem informasi berbasis komputer yang adaptif, interaktif, fleksibel, yang secara khusus dikembangkan untuk mendukung solusi dari pemasalahan manajemen yang tidak terstruktur untuk meningkatkan kualitas pengambilan keputusan. Pada penelitian ini dilakukan perancangan dan pembuatan sistem pendukung keputusan untuk menentukan kualitas beras berbasis android menggunakan metode weighted product, karena melihat banyaknya kelompok tani dan jenis beras yang berbeda-beda.
\end{abstract}

Kata kunci: Android, Beras, Sistem Pendukung Keputusan, Weighted Product

\section{PENDAHULUAN}

Komoditas pangan merupakan salah satu komoditas penting dalam kehidupan manusia. Peranan penting bahan pangan tersebut menjadi dasar untuk perkembangan dunia usaha yang berkaitan dengan komoditas pangan dan bahan olahan dari setiap bahan pangan yang ada. Salah satu komoditas pangan yang 
menjadi bahan pangan dominan di hampir semua negara asia adalah beras, khususnya untuk negara-negara di kawasan Asia Tenggara[1]. Karakter beras secara umum dipengaruhi oleh faktor genetik dan lingkungan. Faktor genetik padi merupakan faktor utama penentu karakter gabah dan beras. Ukuran dan bentuk, warna, pengapuran (chalky), kandungan amilosa-amilopektin, konsistensi gel, suhu gelatinisasi, dan aroma beras merupakan karakter yang diturunkan secara genetik.[2] Faktor lingkungan yang mempengaruhi karakter varietas antara lain adalah butir kuning rusak, butir hijau mengapur, butir retak, dan kadar air beras.

Banyaknya faktor yang membuat kualitas beras berbeda-beda tersebut, dibutuhkannya penilaian pada kualitas beras yang dipanen. Kelompok tani pada Desa Banyumas Kecamatan Stabat memiliki banyak petani padi yang bercocok tanam tanaman padi tersebut. Jenis kualitas beras yang dihasilkan juga berbedabeda tiap daerah kelompok tani pada Desa Banyumas Kecamatan Stabat. Melihat banyaknya kelompok tani dan jenis beras yang berbeda-beda tersebut, dibutuhkannya aplikasi yang dapat melakukan penilaian pada kelompok tani yang bercocok tanam tanaman padi agar dapat memberikan penilaian pada beras yang dihasilkannya. Aplikasi yang akan dibangun ini menggunakan metode weighted product dalam proses pemberian nilai pada masing-masing kelompok tani yang menghasilkan berasnya[3]. Aplikasi juga dibuat dengan berbasis mobile sehingga dapat digunakan dimana saja dengan menggunakan smartphone bersistem operasi android[4].

\section{METODOLOGI PENELITIAN}

Tahapan penelitian yang dilakukan adalah sebagai berikut:

1. Mempersiapkan data kelompok tani yang akan menjadi sampel penelitian.

2. Mengklasifikasikan jenis-jenis beras yang akan diuji kualitasnya.

3. Menentukan kriteria, sub kriteria dan bobot penilaian yang akan dijadikan penilaian kualitas mutu beras.

4. Menerapkan metode weighted product (WP) sebagai salah satu metode dalam sistem pendukung keputusan memilih mutu beras terbaik.

5. Implementasi dalam aplikasi android untuk penerapan metode weighted product (WP).

\section{HASIL DAN PEMBAHASAN}

\subsection{Tahapan Awal Penelitian}

Pada tahapan awal penelitian penulis mengambil sampel penelitian pada satu kelompok tani yang bernama Makmur Jaya yang berlokasi di Desa Banyumas Kecamatan Stabat. Kemudian penulis mengklasifikasikan jenis jenis beras yang akan diuji kualitasnya, Berikut jenis-jenis beras tersebut:

Tabel 1. Klasifikasi Jenis Beras

\begin{tabular}{|c|c|}
\hline Kode Beras & Nama Beras \\
\hline A1 & Malaisya \\
\hline A2 & Sipulo \\
\hline A3 & P6 \\
\hline A4 & Serang \\
\hline
\end{tabular}




\begin{tabular}{|c|c|}
\hline Kode Beras & Nama Beras \\
\hline A5 & Impari \\
\hline A6 & Sitandun \\
\hline A7 & Mentik wangi \\
\hline A8 & Ciherang \\
\hline
\end{tabular}

Setelah klasifikasi jenis beras telah dilakukan, tahapan selanjutnya adalah menentukan kriteria penilaian[5] yang didapat dari proses wawancara dan observasi pada kelompok tani Makmur Jaya.

Tabel 2. Tabel Kriteria Penilaian

\begin{tabular}{|c|c|}
\hline Kode Kriteria & Nama Kriteria \\
\hline C1 & Bentuk \\
\hline C2 & Kebersihan \\
\hline C3 4 & Harga \\
\hline C5 & Warna \\
\hline
\end{tabular}

Untuk menerapkan metode Weighted Product (WP) dibutuhkan sebuah subsub kriteria dan bobot penilaian[6] dari kriteria penilaian yang telah ditentukan.

Tabel 3. Tabel Sub Kriteria dan Bobot Penilaian Kriteria Bentuk

\begin{tabular}{|c|c|}
\hline \multicolumn{2}{|c|}{ Bentuk } \\
\hline Utuh & 1 \\
\hline Patah & 0,8 \\
\hline Butir Mengapur & 0,6 \\
\hline Berkerikil & 0,4 \\
\hline Menir & 0,2 \\
\hline
\end{tabular}

Tabel 4. Tabel Sub Kriteria dan Bobot Penilaian Kriteria Kebersihan

\begin{tabular}{|c|c|}
\hline \multicolumn{2}{|c|}{ Kebersihan } \\
\hline Bersih & 0,6 \\
\hline Kurang Bersih & 0,4 \\
\hline Tidak Bersih & 0,2 \\
\hline
\end{tabular}

Tabel 5. Tabel Sub Kriteria dan Bobot Penilaian Kriteria Harga

\begin{tabular}{|c|c|}
\hline \multicolumn{2}{|c|}{ Harga } \\
\hline$>$ Rp. 15.000 & 1 \\
\hline Rp. $12.000>15.000$ & 0,8 \\
\hline Rp. $10.000>12.000$ & 0,6 \\
\hline Rp. $8.000>10.000$ & 0,4 \\
\hline Rp. $6.000>8.000$ & 0,2 \\
\hline
\end{tabular}

Tabel 6. Tabel Sub Kriteria dan Bobot Penilaian Kriteria Warna

\begin{tabular}{|c|c|}
\hline \multicolumn{2}{|c|}{ Warna } \\
\hline Putih & 0,8 \\
\hline Putih Kekuningan & 0,6 \\
\hline Kuning Muda & 0,4 \\
\hline Coklat & 0,2 \\
\hline
\end{tabular}

Tabel 7. Tabel Sub Kriteria dan Bobot Penilaian Kriteria Tingkat Kepulenan 


\begin{tabular}{|c|c|}
\hline \multicolumn{2}{|c|}{ Kepulenan } \\
\hline Sangat Pulen & 0,8 \\
\hline Pulen & 0,6 \\
\hline Cukup Pulen & 0,4 \\
\hline Tidak Pulen & 0,2 \\
\hline
\end{tabular}

Tahapan selanjutnya adalah menentukan nilai bobot dari masing-masing beras yang datanya didapatkan dari observasi dan wawancara pada kelompok tani Makmur Jaya. Berikut data-data nilai bobot varian beras tersebut :

Tabel 8. Tabel Nilai Bobot Varian Beras

\begin{tabular}{|c|c|c|c|c|c|}
\hline \multirow{2}{*}{ Alternatif (Ai) } & \multicolumn{5}{|c|}{ Kriteria (Ci) } \\
\cline { 2 - 6 } & C1 & C2 & C3 & C4 & C5 \\
\hline Malaisya & 1 & 0,6 & 1 & 0,8 & 0,8 \\
\hline Sipulo & 1 & 0,6 & 0,6 & 0,6 & 0,4 \\
\hline P6 & 0,8 & 0,4 & 0,6 & 0,6 & 0,4 \\
\hline Serang & 0,8 & 0,6 & 0,8 & 0,6 & 0,6 \\
\hline Impari & 0,8 & 0,4 & 0,6 & 0,6 & 0,4 \\
\hline Sitandun & 1 & 0,6 & 0,8 & 0,8 & 0,6 \\
\hline Mentik Wangi & 1 & 0,6 & 0,8 & 0,8 & 0,6 \\
\hline Ciherang & 0,8 & 0,4 & 0,6 & 0,6 & 0,4 \\
\hline
\end{tabular}

\subsection{Implementasi Metode Weighted Product}

Setelah menentukan kriteria dan menentukan rating kecocokan setiap alternatif lalu menyelesaikan perhitungan dengan menggunakan rumus Weighted Product. Sebelum dilakukan perbaikan bobot terlebih dahulu, sehingga total bobot $\sum w j=1$ dengan cara[7] :

$$
\mathrm{W}_{\mathrm{J}}=\frac{W j}{\sum W j}
$$

Dimana :

Wj : W index ke $\mathrm{j}$

$\sum w j$ : jumlah dari W

Dari bobot preferensi sebelumnya yaitu $W=(0.8,1,0.8,0.8,0.6)$ nilai bobot untuk setiap alternatif. Wj merupakan $W$ index ke j. jadi untuk W1 yaitu $0,8, W 2$ yaitu 1 dan seterusnya. Dan $\sum$ wj merupakan jumlah dari $W$ yaitu $(0,8+1+0,8+$ $0,8+0,6)$. Jadi untuk perbaikan bobot W1 menjadi

$$
\begin{aligned}
W 1 & =\frac{0,8}{0,8+1+0,8+0,8+0,6} \\
& =\frac{0,8}{4} \\
& =0,2 \\
W 2 & =\frac{1}{0,8+1+0,8+0,8+0,6} \\
& =\frac{1}{4}
\end{aligned}
$$

$$
\begin{aligned}
& =0,25 \\
\text { W3 } & =\frac{0,8}{0,8+1+0,8+0,8+0,6} \\
& =\frac{0,8}{4} \\
& =0,2 \\
\text { W4 } & =\frac{0,8}{0,8+1+0,8+0,8+0,6}
\end{aligned}
$$




$$
\begin{aligned}
& =\frac{0,8}{4} \\
& =0,2 \\
W 5 & =\frac{0,6}{0,8+1+0,8+0,8+0,6}
\end{aligned}
$$$$
=\frac{0,6}{4}
$$$$
=0,15
$$

Menetukan nilai vector Si yang dapat dihitung menggunakan formula berikut[8] :

$$
\mathrm{s}_{\mathrm{i}}=\prod_{J=1}^{n} X_{i j} \mathrm{w}_{\mathrm{j}}
$$

Dimana :

$\mathrm{V}$ : Preferensi alternatif,

$\mathrm{X}$ : Nilai kriteria,

$\mathrm{w}$ : Bobot kriteria.

Untuk perhitungan sederhananya kembali lihat table nilai alternatif dan kriteria pada baris R1, masing-masing kriteria memiliki nilai sebagai berikut:

$$
\begin{aligned}
& \text { C1 }=1 \\
& \text { C2 }=0,6 \\
& \text { C3 }=1 \\
& \text { C4 }=0,8 \\
& \text { C5 }=0,8
\end{aligned}
$$

Pangkatkan dan kalikan nilai masing-masing kriteria tersebut dengan bobot yang sudah diperbaiki sebelumnya menjadi seperti berikut :

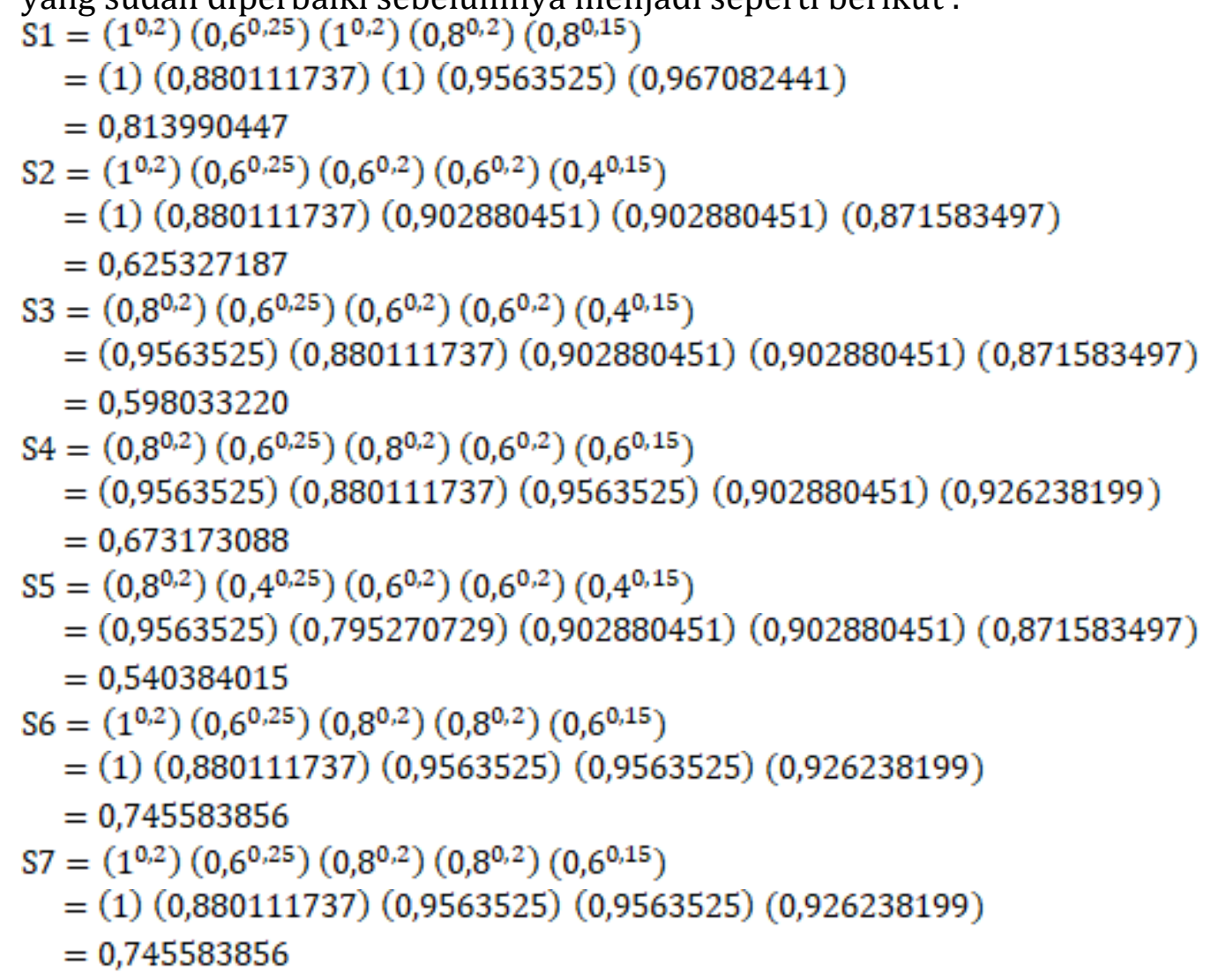




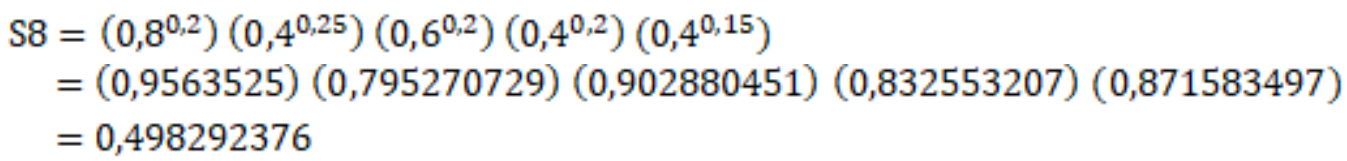
berikut.

Dan hasil dari proses normalisasi sehingga di dapat hasil normalisasi sebagai Tabel 9. Tabel Nilai Si

\begin{tabular}{|c|c|}
\hline Si & Nilai Si \\
\hline S1 & 0,813990447 \\
\hline S2 & 0,625327187 \\
\hline S3 & 0,598033220 \\
\hline S4 & 0,673173088 \\
\hline S5 & 0,540384015 \\
\hline S6 & 0,745583856 \\
\hline S7 & 0,745583856 \\
\hline S8 & 0,498292376 \\
\hline
\end{tabular}

Menentukan nilai vector yang akan digunakan mengehitung preferensi (Vi) untuk perangkingan adalah sebagai berikut

$$
V 1=\frac{\mathrm{S} 1}{\mathrm{~S} 1+\mathrm{S} 2+\mathrm{S} 3+\mathrm{S} 4+\mathrm{S} 5+\mathrm{S} 6+\mathrm{S} 7+\mathrm{S} 8}
$$

Jadi hasil dari menghitung preferensi (Vi) adalah sebagai berikut :

$$
\begin{aligned}
& \mathrm{V} 1=\frac{0,813990447}{0,813990447+0,625327187+0,598033220+0,673173088+} \\
& 0,540384015+0,745583856+0,745583856+0,498292376 \\
& =\frac{0,813990447}{5,24036805} \\
& =0,155330778 \\
& V 2=\frac{0,625327187}{0,813990447+0,625327187+0,598033220+0,673173088+} \\
& 0,540384015+0,745583856+0,745583856+0,498292376 \\
& =\frac{0,625327187}{5,24036805} \\
& =0,119328868 \\
& \mathrm{~V} 3=\frac{0,598033220}{0,813990447+0,625327187+0,598033220+0,673173088+} \\
& 0,540384015+0,745583856+0,745583856+0,498292376 \\
& =\frac{0,598033220}{5,24036805} \\
& =0,114120461 \\
& \mathrm{~V} 4=\frac{0,673173088}{0,813990447+0,625327187+0,598033220+0,673173088+} \\
& 0,540384015+0,745583856+0,745583856+0,498292376 \\
& =\frac{0,673173088}{5,24036805}
\end{aligned}
$$




$$
\begin{aligned}
& =0,128459124 \\
& \mathrm{~V} 5=\frac{0,540384015}{0,813990447+0,625327187+0,598033220+0,673173088+} \\
& 0,540384015+0,745583856+0,745583856+0,498292376 \\
& =\frac{0,540384015}{5,24036805} \\
& =0,103119477 \\
& \text { V6 }=\frac{0,745583856}{0,813990447+0,625327187+0,598033220+0,673173088+} \\
& 0,540384015+0,745583856+0,745583856+0,498292376 \\
& =\frac{0,745583856}{5,24036805} \\
& =0,142277002 \\
& V 7=\frac{0,745583856}{0,813990447+0,625327187+0,598033220+0,673173088+} \\
& 0,540384015+0,745583856+0,745583856+0,498292376 \\
& =\frac{0,745583856}{5,24036805} \\
& =0,142277002 \\
& V 8=\frac{0,498292376}{0,813990447+0,625327187+0,598033220+0,673173088+} \\
& 0,540384015+0,745583856+0,745583856+0,498292376 \\
& =\frac{0,498292376}{5,24036805} \\
& =0,0950872861
\end{aligned}
$$

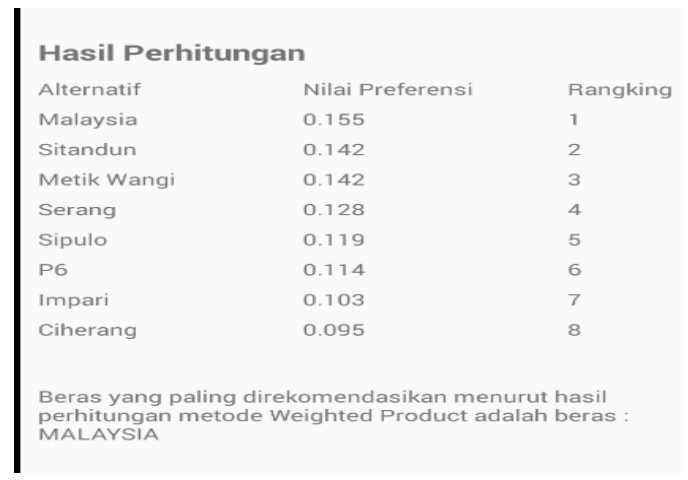

Gambar 1. Hasil Perhitungan dan Perangkingan

\subsection{Implementasi Pada Aplikasi Android}

Adapun alat yang digunakan untuk mengimplementasikan sistem kendali mutu beras pada kelompok tani ke dalam aplikasi android[9] yaitu :

1) Software Android Studio.

2) Sistem Operasi Windows 10.

3) Smartphone Android dengan Sistem Operasi Minimal Marshmallow [10]. 


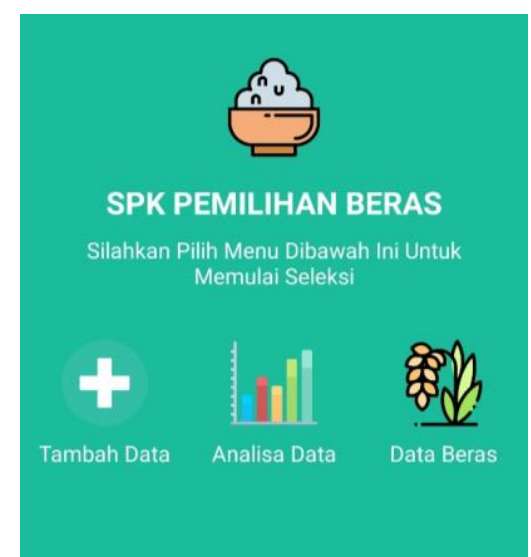

Gambar 2. Tampilan Aplikasi Android

\section{KESIMPULAN}

Dari hasil penelitian yang dilakukan pada masalah sistem kendali mutu beras pada kelompok tani berbasis sistem pendukung keputusan dapat kami simpulkan bahwa sistem ini dapat membantu dalam menilai kualitas beras pada kelompok tani Makmur Jaya Desa Banyumas. Sistem kendali mutu beras ini diharapkan dapat menjaga kualitas beras yang disalurkan melalui kelompok tani Makmur Jaya sehingga masyarakat dapat memperoleh beras yang berkualitas dan bergizi. Sistem ini juga sangat praktis karena dapat digunakan pada Smartphone Android sehingga dapat dijalankan kapanpun dan dimanapun. Diharapkan kedepannya aplikasi ini dapat menjadi sistem kendali mutu beras pada banyak kelompok tani bukan hanya di Desa Banyumas, Tapi meliputi wilayah Kecamatan Stabat.

\section{DAFTAR PUSTAKA}

[1] R. Pontoh et al., "Permintaan Dan Penawaran Beras Di Indonesia ( Pada Tahun 2003 Tahun 2013 )," vol. 16, no. 04, pp. 833-844, 2016.

[2] I. Karakteristik, J. Barat, P. Wibowo, and S. D. Indrasari, "Identifikasi Karakteristik dan Mutu Beras di Jawa Barat," pp. 43-49, 2009.

[3] M. Program et al., "METODE WEIGHTED PRODUCT ( STUDI KASUS :,” pp. 19-22, 2013.

[4] B. U. Fahnun, R. Noviana, L. Prananingrum, and E. Tjioe, "Informasi kampus berbasis web pada android," pp. 25-32, 2013.

[5] R. B. U. Khairul, "Seleksi Pegawai Kontrak Menjadi Pegawai Tetap Dengan Metode Profile Matching," vol. 2, no. 2, pp. 68-77, 2018.

[6] K. B. Bolango, "Penerapan Metode Weighted Product ( WP ) Berbasis Sistem Pengambilan Keputusan Untuk Pemberian Dana Bantuan Mandiri Desa Wisata pada Dinas Perhubungan Pariwisata," pp. 56-62.

[7] J. I. Mulawarman, N. Nurjannah, Z. Arifin, and D. M. Khairina, "SEPEDA MOTOR DENGAN METODE WEIGHTED PRODUCT," vol. 10, no. 2, pp. 2-6, 2015.

[8] S. Rani and M. S. Scott, "Sistem pendukung keputusan pemilihan sepeda motor berbasis web denga metode weighted product," pp. 62-66, 2014.

[9] M. Rochman, W. Maulana, A. P. Java, M. Sheridan, and J. Gosling, "Pengembangan Aplikasi Android Untuk Studi Bahasa Carakan Madura," vol. 01, pp. 32-39.

[10] R. N. Farizah, "Pemodelan aplikasi mobile reminder berbasis android," vol. 2016, no. Sentika, pp. 18-19, 2016. 